\section{Gender selection sparks row}

Tokyo

A GROUP at Keio University in Tokyo has caused a sensation by claiming a major medical scoop on national television last month, when it announced that six married woman had given birth to baby girls after artificial insemination with Xchromosome sperms separated by centrifugation. But the publicity has back-fired, and the Keio team has come under a barrage of criticism even from within their own university for failing to inform the public of the experiments, and for going ahead without first discussing the ethical questions raised by sex selection.

The ethical committee of Keio University met last week and decided that once the reliability of the method has been established, it should be used only to prevent hereditary diseases. In the meantime, practitioners around Japan have already started using the technique.

Soon after the Keio group made its announcement, a group promoting sex selection headed by Dr Shiro Sugiyama, owner of Sugiyama Gynecology Clinic in Tokyo, revealed that 40 girls had been born around the nation using the Keio technique, and out of 24 women who conceived, 22 gave birth to girls, a success rate of over 90 per cent.

The principle of the technique is simple enough and well known - X-chromosome sperms are marginally more dense than those with $\mathrm{Y}$ chromosomes because of the larger size of the former chromosome, and they can, in theory, be separated by centrifugation. Although many claims of successful sex selection based on this principle have been made, no reliable technique has yet emerged. The Keio team, headed by Professor Rihachi Iizuka of Keio University and Professor Hideo Mori of Tokyo University, described their method in 1984 (Biomedical Research, 5, $187 ; 1984)$.

The secret lies in the fluid in which the sperm are suspended for centrifugation. A density gradient of Percoll, a modified silica gel, is used and the sperm are separated on the basis of differential velocity sedimentation. After a 20-30-minute spin in a centrifuge at $250 \mathrm{~g}, 95-100$ per cent of the sperm in the bottom layer carries the $\mathrm{X}$ chromosome, while the overlying layer has about 85 per cent sperm containing the $\mathrm{Y}$ chromosome. According to Sugiyama, it is then just a simple matter of pricking a hole in the bottom of the centrifuge tube and draining a few drops of the X-chromosome-rich sperm which are used for impregnation.

First treatment in the Sugiyama Clinic costs 50,000 yen (about $£ 170$ ) and, in the case of failure, each subsequent treatment is 20,000 yen. Four or five attempts are usually required for success.

Sugiyama heads the Sex Selection Research Group which was established 7 years ago and which has 770 practising gynaecologist members throughout the nation. In the past they used vinegarrinsing of the vagina as a technique to promote the conception of girls. But success was "less than 80 per cent".

According to Sugiyama, the new method has been used in most cases to prevent hereditary diseases such as haemophilia which occur in men, but he admitted some parents wanted a girl for personal reasons, such a wanting to raise their child to be a ballerina. It is revelations like this that have raised a furore.

Iizuka also initially claimed that the technique had been applied to avoid hereditary diseases, but many Japanese colleagues questioned this and Professor Yasuo Uemura, head of Keio University ethics committee, criticized the Keio team for applying the technique to couples who simply wanted a girl because they already had boys.

Uemura also though it "regrettable" that Iizuka went ahead without consulting the ethics committee in advance and "imprudent" that some of the members of his team attended meetings of obstetrical practitioners to teach them the sex-selection method.

Immediately after the meeting of the
Keio University ethics committee, Sugiyama said he would abide by the committee's decision and limit application of the technique to prevention of hereditary diseases.

But in a complete about-turn a few days later he declared that he would continue to help ordinary parents to select the sex of their babies until advised otherwise by nationwide medical organizations, such as the Japan Medical Association or the Japan Society of Obstetrics and Gynecology. His change of heart came because he was deluged with letters and telephone calls from people asking him to continue the technique, and he felt it was "his duty as medical practitioner" to respect the wishes of such people.

According to a report in Shukan Bunshun, a Japanese weekly publication, the Keio group started clinical trials of the technique in May last year, and for the past six months Japan's national broadcasting corporation, Nihon Hoso Kyokai (NHK), has been allowed to cover the research.

But a difference of opinion arose between the Keio group and NHK about when to release the news; NHK felt that the preliminary success of the technique raised important social issues which should be discussed in public while the Keio team wanted to test about 100 women to obtain statistically reliable results.

In the end, NHK was allowed to broadcast after the successful birth of six girls by the Keio technique.

\title{
Brown eggs catch on in Japan
}

Tokyo

FIRST it was the Australian "superpig" and now comes Japan's "biochicken", the next contender in the farmyard biotech race. And what makes biochicken special? She lays brown eggs, lots of them.

That may not sound like much of a feat until one realizes that shiny reddish brown eggs (literally "red eggs" in Japanese) command twice the price of the paler white variety on the Japanese domestic market. The inflated price of brown eggs in Japan can be attributed to limited supply and a belief among the general public that brown eggs are more nutritious.

Quick to spot a potential money-maker, scientists at Nagoya University and the Agricultural Experiment Station of Aichi prefecture have created White Leghorn hens that lay brown eggs instead of their usual white ones. Ths is achieved by false fertilization.

Sperm of a Rhode Island Red rooster, which carries the gene for brown eggs, is first irradiated with gamma radiation to inactivate it. The sperm is then allowed to enter the egg of a White Leghorn, thereby introducing some Rhode Island
Red genetic material into the egg which is then fertilized with normal White Leghorn sperm. About 7 per cent of the fertilized eggs result in chickens that lay brown eggs. This technique was developed in New Zealand in 1982 by Pandey, but it had no commercial applications there - in New Zealand brown eggs cost the same as white.

But why go to all this trouble when Rhode Island Reds already lay brown eggs? The answer lies in greater productivity - the White Leghorn is a profuse egg layer. No doubt also, the label "bioeggs" will have commercial appeal in this country where "biolipstick" has swamped the cosmetic market (see Nature 314,395 ; 1985).

Biochicken, however, is not yet quite living up to expectations; her eggs are only pale brown and are more typical of a hybrid White Leghorn/Rhode Island Red than a true Rhode Island Red.

But by selective breeding the Japanese team is confident that by this autumn it can come up with a hen that lays pure brown eggs, and it has already named this chicken of the future the "Aichi Bio Red". David Swinbanks 